www.jmscr.igmpublication.org

Impact Factor (SJIF): 6.379

Index Copernicus Value: 71.58

ISSN (e)-2347-176x ISSN (p) 2455-0450

crossrefDOI: https://dx.doi.org/10.18535/jmscr/v6i6.35

Journal Of Medical Science And Clinical Research

\title{
Depression among general outpatients: A cross sectional study at Yobe State Specialist Hospital, Damaturu, North East Nigeria
}

Authors

Oderinde Kehinde Oyeyemi ${ }^{1}$, Dada Mobolaji Usman ${ }^{2}$, Kundi Babagana Machina ${ }^{3}$, Tsuung Ason Benjamin ${ }^{4}$, Dahiru Asmau Mohammed Chubado5, Ahmed Hauwa Kudale ${ }^{5}$, Tanko Salihu Tanimu6, Yusuff Alhaji Abdulkareem ${ }^{6}$, Ezra-Oderinde Wonderful Efosa ${ }^{7}$, Awunor Nyemike Simeon ${ }^{8}$

${ }^{1}$ Department of Mental Health and Substance Addiction Treatment, Yobe State University Teaching Hospital, Damaturu, Nigeria

${ }^{2}$ Department of Psychiatry, Ekiti State University Teaching Hospital, Ado Ekiti, Nigeria

${ }^{3}$ Department of Psychiatry, Yobe State Specialist Hospital, Damaturu, Nigeria

${ }^{4}$ Department of Family Medicine, Yobe State University Teaching Hospital, Damaturu, Nigeria

${ }^{5}$ Department of Mental Health, Federal Neuro-Psychiatric Hospital, Maiduguri, Nigeria

${ }^{6}$ Department of Family Medicine, Aminu Kano Teaching Hospital, Kano, Nigeria

${ }^{7}$ Clinical Psychology Unit, Federal Neuro-Psychiatric Hospital, Uselu, Benin City, Nigeria

${ }^{8}$ Department of Community Medicine, College of Health Sciences, Delta State University, Abraka, Delta

State, Nigeria

Corresponding Author

Dr Oderinde Kehinde Oyeyemi

Department of Mental Health and Substance Addiction Treatment, Yobe State University Teaching Hospital Damaturu, Nigeria.

Email: psymedrecoverycentre@gmail.com, Phone no: 08035281062

\begin{abstract}
Background: Depression is the most common psychiatric disorder among general outpatients. It has been studied in most parts of Nigeria, however there is paucity of data in the insurgency ravaged geopolitical zone of Nigeria i.e north east Nigeria, hence the need to bring into limelight this public health problem.

The objectives of the study were to determine the prevalence of depression, socio demographic and clinical variables associated with depression among general outpatients in Yobe State Specialist Hospital, Damaturu, North East Nigeria.

Materials and Methods: A cross sectional descriptive survey was conducted between August and December 2017 among patients who attended the General Out Patient Department of Yobe State Specialist Hospital, Damaturu, Nigeria. Out of the 420participants recruited for the study, 404 respondents completed the study. Data was collected using a semi structured questionnaire for socio demographic characteristics of respondents and depression was assessed by the physicians using Patient Health Questionnaire-9.
\end{abstract}

Results: Data was analyzed using SPSS version 21. The age of the respondents ranged between 18 to 60 
years and above with a mean age of 41.2_+9.5years. The prevalence of depression was $65.3 \%$ among the study population. There was a statistically significant association between age $(P=0.007)$, sex $(P=0.004)$, marital status $(P<0.001)$, educational status $(<0.001)$, number of children $(P<0.001)$, relationship tone with the spouse $(P<0.001)$, family history of mental illness $(P<0.001)$, monthly income $(P<0.001)$ and depression in respondents. There was no statistically significant association between having a specific medical disorder and depression status of respondents $(P=0.996)$.

Conclusion: The study revealed the high magnitude of depression that goes undiagnosed and unmanaged. It was suggested that general medical practitioners do thorough assessment for early detection and prompt referral of patients with depression among general outpatients.

Keywords: Depression, General Outpatients, North East Nigeria.

\section{Introduction}

Depression is predicted to become the second leading cause of the global disease burden by the year $2020^{1}$. According to the World Federation of Mental report of 2012, depression interferes with the daily life of people and causes pain for both patients and their carers ${ }^{2}$. Evidence indicates that mood disorders are among the most common problems that bring patients to doctors, thus literature from high income country suggest that almost $20 \%$ of adults will have a mood disorder requiring treatment during their lifetime while about $8 \%$ of adults will have a major depressive disorder during their lives ${ }^{3}$.

Depression, a mood disorder is known to occur at high rates in patients who seek general medical care and nearly $70 \%$ of all antidepressants prescriptions are written by primary care physicians ${ }^{4}$. The World Health Organization report on mental health suggest that undiagnosed depression among general outpatients places a significant socio economic burden on individuals, families and communities, in terms of increased service needs, lost employment, reduced productivity and increased burden on caregivers ${ }^{5}$.

The ability to detect depression by clinicians is sometimes affected by co morbidity. The co morbidity of physical illnesses and depression often complicates diagnosis, treatment and prognosis of depression ${ }^{6}$.

The presence of multiple somatic symptoms in general medical practice further confuse the diagnosis and the priority of treatment given to the patients ${ }^{7}$. Somatic manifestations of depression also occurs across all cultures and contribute to the under recognition of depression in general practice $^{7}$. Despite the findings on these studies on this co morbidity, little time is available to screen for mental disorders due to the workload at general medical outpatient clinics, hence depression may go undiagnosed. Notably, the prevalence of depression is higher in patients than in the general public ${ }^{8}$, the underlying reasons include the illness itself and the heavy medical cost, unsatisfactory medical care service and poor doctor-patient relationship ${ }^{9}$.

Depression among general outpatients has been studied by many researchers in Nigeria and other parts of the world. A study by Afolabi et $\mathrm{al}^{10}$ reported the prevalence of depression as $59.6 \%$ on a sample of 250 patients at the family practice clinic of Obafemi Awolowo University Teaching Hospital, Ile Ife, Nigeria where they used Zung's Self Rating Depression Scale. Another study conducted by Michael Udedi ${ }^{11}$ in 2014 found the prevalence of depression as $30.3 \%$ among 350 patients attending general outpatient at Matawale Health Centre in Zomba, Malawi using Self Reporting Questionnaire (SRQ-20) and Structured Clinical Interview for DSM-IV axis 1 Disorders Non Patient Version (SCID-NP). A more recent study by Salihu and Udofia ${ }^{12}$ in Kano, North West Nigeria reported the prevalence as $49.8 \%$ and they found that depressed outpatient is more likely to be over 40years, female, married, having low level of education and suffering from chronic medical condition.

Direct comparison of prevalence estimates for depressive disorders is difficult because of a lack of uniformity as studies differ in terms of culture, patient population, sociodemographic factors and 
methodology ${ }^{13}$. This study seeks to to determine the prevalence of depression and the variables associated with depression among general outpatients in Yobe State Specialist Hospital, Damaturu, North East Nigeria.

\section{Materials and Methods}

\subsection{Setting of Study}

The location of the study was in the General Out Patient Clinic of the State Specialist Hospital, Damaturu in the North Eastern geographical zone of Nigeria. The hospital is a 339 bed general public hospital providing primary, secondary and tertiary health care needs of the population of Yobe State, neighbouring states and the West African sub region as well. It is among the busiest health facility in the north eastern region of Nigeria with an average outpatient attendance of 300patients per day. There are different units and clinics in the hospital providing specialist services for patients through the aid of full time and visiting consultants.

\subsection{Study design}

The study was a cross sectional descriptive survey of consecutive patients who presented at the General Out Patient Department of the hospital until the estimated sample size of 420 was obtained. The study was carried out between August 2017 and December 2017. All newly registered patients who attended the clinic during the period of the study were also included. Data was collected using questionnaire incorporating socio demographic variables and depression was assessed with the Patient Health Questionnaire-9. The primary clinical diagnosis of the patients was made by attending physicians and these were classified into: (1) Infectious diseases e.g malaria, typhoid and others not specific to any System (2) Cardiovascular disorders e.g hypertension (3) Respiratory disorders (4) Gastrointestinal disorders (5) Genitourinary diseases (6) Musculoskeletal disorders (7) Endocrine disorders e.g diabetes (8 and 9) Others including dermatological disorders, ear, eye, neurological and other non specific diagnoses.

\subsection{Ethical consideration}

An approval for the study was obtained from the Research and Ethical Committee of Yobe State Specialist Hospital, Damaturu. Participation was made voluntary and informed consent was freely obtained from the respondents. Confidentiality was also ensured and respondents were assured that their healthcare would not be affected by whether or not they participated.

\subsection{Sample size determination}

The sample size that was used for the study was computed based on the formula

$\mathrm{n}=\mathrm{Z}^{2} \mathrm{p}(1-\mathrm{p}) / \mathrm{d}^{2}$

$\mathrm{n}=$ minimum sample size

$\mathrm{P}=$ prevalence of depression among general outpatients

$\mathrm{Z}=$ the standard normal deviation at $95 \%$ confidence level (1.96)

$\mathrm{d}=$ maximum allowable margin of error which is set at $5 \%(0.05)$

The prevalence rate of $49 \%$ of depression in general medical practice in Nigeria by Salihu and Udofia $^{12}$ was employed in this study. Thus

$$
\begin{aligned}
P & =0.49 \\
Z & =1.96 \\
d & =0.05 \\
n & =(1.96)^{2} \times 0.49 \times 0.51 /(0.05)^{2} \\
& =384.01
\end{aligned}
$$

Adjusting for non response rate of $10 \%$ gave a minimum sample size of $384.01+38.40=422.4$

Approximately, an estimated sample size of 420 was obtained.

\subsection{Inclusion and exclusion criteria}

Respondents were eligible for participation if they:

1. Were 18years and above

2. Gave consent

Respondents were not eligible if they:

1. Were severely ill with debilitating illness 
2. Were receiving treatment for any psychiatric disorder.

3. Refused to give consent.

\subsection{Instruments}

1. Socio demographic questionnaire

2. Patient Health Questionnaire-9 (PHQ-9)

The questionnaires were administered by the investigators and research assistants.

\subsubsection{Socio demographic questionnaire}

The semi structured socio demographic questionnaire was designed for the study to elicit information on socio demographic variables such as age, sex, religion, marital status, level of education and employment status. The questionnaire also contained questions on family size and relationship with spouses in the family.

\subsubsection{Patient Health Questionnaire-9}

This is a nine item depression scale screening instrument. It is useful in screening for depression as well as selecting and monitoring treatment. It scores each of the nine DSM-IV criteria as ' 0 ' (not at all) to ' 3 '(nearly every day). It has been validated for use in Nigeria by Adewuya et $\mathrm{al}^{15}$. The PHQ-9 scores of 5-9, 10-14, 15-19 and 20-27 represent mild, moderate, moderately severe and severe depression respectively. In this study, a cut off of 5 was employed as cut off for depression as recommended by Adewuya et $\mathrm{al}^{14}$.

\subsection{Data collection and analysis}

\subsubsection{Pilot Study}

The questionnaires were pre-tested using forty two patients ( $10 \%$ of the sample size) in Yobe State University Teaching Hospital, Damaturu who did not participate in the main study. The aim of this pilot study was to ensure that these questionnaires could reliably be used among the target sample to be recruited for the study.

\subsubsection{Data collection}

With the informed consent of each consecutive respondent, the proforma for socio demographic data was administered by the authors and depression was assessed using Patient Health Questionnaire. This was done in the consultation rooms of the clinic every day until the desired sample size of 420 was obtained.

\subsubsection{Data analysis}

Data analysis was carried out using the Statistical Package for Social Sciences version 21 software. Appropriate descriptive and inferential statistics were used for the data collected to achieve the objectives of the study. Univariate analysis was used to determine the prevalence of depression and this was expressed in percentages. Association of bivariate levels was assessed using t test, chi square and Pearson's correlation coefficient based on the type of variable.

\section{Results}

Four hundred and twenty (420) participants were selected for the study. However, four hundred and four $(96.2 \%)$ of them finally participated and had complete data sets without any missing data on the variables.

The mean (SD) age of respondents was 41.2 (9.5) years. Table 1 shows most respondents were females $(63.7 \%)$, majority were muslims $(83.2 \%)$, were married $(74.0 \%)$ and a high proportion were of the Kanuri ethnic group (56.2\%). About a third had no formal education (33.4\%) and more than half $(53 \%)$ of the respondents were unemployed. A significant proportion of the respondents came from polygamous family settings $(62.1 \%)$ and most respondents $(59.9 \%)$ had monthly income below Nigerian minimum wage of 50USD. The mean (SD) USD monthly income of respondents was 64.90 (76.96) and the median monthly income was 50USD only. 
Table 1a: Socio-demographic characteristics of respondents $(n=404)$

\begin{tabular}{|c|c|c|}
\hline Characteristic & Frequency & Percent \\
\hline \multicolumn{3}{|l|}{ Ages (yrs) } \\
\hline$<30$ & 62 & 15.3 \\
\hline $30-39$ & 129 & 31.9 \\
\hline $40-49$ & 143 & 35.4 \\
\hline $50-59$ & 48 & 11.9 \\
\hline 60 and above & 22 & 5.4 \\
\hline Mean (SD) yrs & 41.2(9.5) yrs & \\
\hline \multicolumn{3}{|l|}{ Sex } \\
\hline Male & 146 & 36.1 \\
\hline Female & 258 & 63.9 \\
\hline \multicolumn{3}{|l|}{ Religion } \\
\hline Islam & 336 & 83.2 \\
\hline Christianity & 65 & 16.1 \\
\hline Other & 3 & 00.7 \\
\hline \multicolumn{3}{|l|}{ Marital status } \\
\hline Single & 30 & 07.4 \\
\hline Married & 299 & 74.0 \\
\hline Separated & 26 & 06.4 \\
\hline Divorced & 23 & 05.7 \\
\hline Widowed & 26 & 06.4 \\
\hline \multicolumn{3}{|l|}{ Ethnic group } \\
\hline Kanuri & 227 & 56.2 \\
\hline Hausa & 98 & 24.3 \\
\hline Fulani & 41 & 10.1 \\
\hline Yoruba & 16 & 4.0 \\
\hline Igbo & 10 & 2.5 \\
\hline Others & 12 & 3.0 \\
\hline \multicolumn{3}{|l|}{ Educational status } \\
\hline No formal education & 135 & 33.4 \\
\hline Primary & 107 & 26.5 \\
\hline Secondary & 81 & 20.0 \\
\hline Tertiary & 81 & 20.0 \\
\hline \multicolumn{3}{|l|}{ Employment status } \\
\hline Employed & 190 & 47.0 \\
\hline Unemployed & 214 & 53.0 \\
\hline \multicolumn{3}{|l|}{ Family Type } \\
\hline Polygamous & 251 & 62.1 \\
\hline Monogamous & 153 & 37.9 \\
\hline \multicolumn{3}{|l|}{ No. of children } \\
\hline None & 7 & 1.7 \\
\hline $1-4$ & 149 & 36.9 \\
\hline $5-8$ & 107 & 26.5 \\
\hline 9 and above & 141 & 34.9 \\
\hline \multicolumn{3}{|c|}{ Monthly income (USD) } \\
\hline$<50$ USD & 242 & 59.9 \\
\hline 50USD and above & 162 & 40.1 \\
\hline
\end{tabular}

Table 1b: Summary statistics of select numeric variables

\begin{tabular}{lccc}
\hline & Mean & SD & Median \\
\hline Variable & 41.2 & 9.5 & 41.0 \\
Monthly salary (in USD) & 64.90 & 76.96 & 50.00 \\
Depression score & 6.0 & 2.8 & 6.0 \\
\hline
\end{tabular}

Table 2 shows majority of respondents reported no family history of mental illness $(79.5 \%)$ and almost half of the respondents reported a chronic medical condition (49.5\%). Most respondents reported a cordial relationship tone with their spouses $(54.2 \%)$ and most respondents, following 
assessment, were reported as depressed (65.3\%).

was $264(65.3 \%)$

The prevalence of depression among respondents

Table 2: Health related characteristics of respondents $(n=404)$

\begin{tabular}{lcc}
\hline Characteristics & Frequency & Percent \\
\hline Family history of mental illness & 83 & \\
Yes & 321 & 20.5 \\
No & & 79.5 \\
Chronic medical condition & 200 & \\
Yes & 204 & 49.5 \\
No & & 50.5 \\
Relationship tone with spouse & 45 & \\
Not applicable & 219 & 11.1 \\
Cordial & 140 & 54.2 \\
Not cordial & & 34.7 \\
Depression status & 140 & \\
Non depressed & 264 & 34.7 \\
Depressed & & 65.3 \\
\hline
\end{tabular}

Table 3 shows a little above a third of respondents presented on account of infective disorders (33.4\%), followed by cardiovascular $(23.3 \%)$ and others including dermatological disorders, ear, eye, neurological and other non specific diagnoses $(9.2 \%)$

Table 3: Distribution of medical disorders among patients attending the outpatient clinic

\begin{tabular}{lcc}
\hline Characteristics & Frequency & Percent \\
\hline Infective disorder & 135 & 33.4 \\
Cardiovascular disorder & 94 & 23.3 \\
Endocrine disorder & 36 & 8.9 \\
Gastrointestinal disorder & 29 & 7.2 \\
Respiratory disorder & 27 & 6.7 \\
Musculoskeletal disorder & 26 & 6.4 \\
Genitourinary disorder & 20 & 5.0 \\
Others & 37 & 9.2 \\
Total & $\mathbf{4 0 4}$ & $\mathbf{1 0 0 . 0}$ \\
\hline
\end{tabular}

Table 4 shows there was a statistically significant association between age $(\mathrm{P}=0.007)$, sex $(\mathrm{P}=0.004)$, marital status $(\mathrm{P}<0.001)$, educational status $(<0.001)$, number of children $(\mathrm{P}<0.001)$, relationship tone with spouse $(\mathrm{P}<0.001)$, family history of mental illness $(\mathrm{P}<0.001)$, monthly income $(\mathrm{P}<0.001)$, family type $(\mathrm{P}<0.001)$, employment status $(\mathrm{P}<0.001)$ and depression in respondents. 
Table 4: Socio-demographic characteristics and Depression status in respondents

\begin{tabular}{|c|c|c|c|c|}
\hline Characteristic & $\begin{array}{c}\text { Non depressed } \\
\text { n }(\%)\end{array}$ & $\begin{array}{c}\text { Depressed } \\
\text { n }(\%)\end{array}$ & $\mathbf{X}^{2}$ & P-value \\
\hline \multicolumn{5}{|l|}{ Age (in years) } \\
\hline$<30$ & $22(35.5)$ & $40(64.5)$ & 13.992 & $* 0.007$ \\
\hline $30-39$ & $58(45.0)$ & $71(55.0)$ & & \\
\hline $40-49$ & $43(30.1)$ & $150(69.9)$ & & \\
\hline $50-59$ & $15(31.3)$ & $33(68.8)$ & & \\
\hline$>60$ & $2(09.1)$ & $20(90.9)$ & & \\
\hline \multicolumn{5}{|l|}{ Sex } \\
\hline Male & $64(43.8)$ & $82(56.2)$ & & \\
\hline Female & $76(29.5)$ & $182(70.5)$ & 8.512 & $* 0.004$ \\
\hline \multicolumn{5}{|l|}{ Religion } \\
\hline Islam & $115(33.8)$ & $225(66.2)$ & & \\
\hline Christianity & $24(39.3)$ & $37(60.7)$ & 0.698 & 0.705 \\
\hline \multirow{2}{*}{\multicolumn{5}{|c|}{ Marital status }} \\
\hline & & & & \\
\hline Unmarried & $15(14.3)$ & $90(85.7)$ & & \\
\hline Married & $125(41.8)$ & $174(58.2)$ & 25.991 & $*<0.001$ \\
\hline \multicolumn{5}{|l|}{ Ethnic group } \\
\hline Kanuri & 83. (36.6) & $144(63.4)$ & & \\
\hline Hause & $35(35.7)$ & $63(64.3)$ & 4.013 & 0.548 \\
\hline Fulani & $9(22.0)$ & $32(78.0)$ & & \\
\hline Yoruba & $6(37.5)$ & $10(62.5)$ & & \\
\hline Igbo & $4(40.0)$ & $6(60.0)$ & & \\
\hline Others & $3(25.0)$ & $9(75.0)$ & & \\
\hline \multicolumn{5}{|l|}{ Educational status } \\
\hline No formal educ. & $98(72.6)$ & $37(27.4)$ & & \\
\hline Primary & $2(1.9)$ & $105(98.1)$ & 159.398 & $*<0.001$ \\
\hline Secondary & $8(9.9)$ & $73(90.1)$ & & \\
\hline Tertiary & $32(39.5)$ & $49(60.5)$ & & \\
\hline \multicolumn{5}{|l|}{ Employment status } \\
\hline Employed & $124(65.3)$ & $66(34.7)$ & & \\
\hline Unemployed & $16(7.5)$ & $198(92.5)$ & 148.412 & $*<0.001$ \\
\hline \multicolumn{5}{|l|}{ Family Type } \\
\hline Polygamous & $33(13.1)$ & $218(86.9)$ & & \\
\hline Monogamous & $107(69.9)$ & $46(30.1)$ & 135.368 & $*<0.001$ \\
\hline \multicolumn{5}{|l|}{ No of children } \\
\hline None & $3(42.9)$ & $4(57.1)$ & & \\
\hline $1-4$ & $117(78.5)$ & $32(21.5)$ & & \\
\hline $5-8$ & $16(15.0)$ & $91(85.0)$ & & \\
\hline 9 and above & $4(2.8)$ & $137(97.2)$ & 218.71 & $*<0.001$ \\
\hline \multicolumn{5}{|l|}{ Relationship tone with spouse } \\
\hline Not applicable & $7(15.6)$ & $38(84.4)$ & & \\
\hline Good & $128(58.4)$ & $91(41.6)$ & 121.729 & $*<0.001$ \\
\hline Poor & $5(03.6)$ & $135(96.4)$ & & \\
\hline \multicolumn{5}{|l|}{ Family history of mental } \\
\hline Yes & $15(18.1)$ & $68(81.9)$ & & \\
\hline No & $125(38.9)$ & $196(61.1)$ & 12.683 & $*<0.001$ \\
\hline \multicolumn{5}{|l|}{ Monthly income (USD) } \\
\hline$<50$ & $4(01.7)$ & $237(98.3)$ & & \\
\hline$>50$ & $136(84.0)$ & $26(16.0)$ & 289.372 & $*<0.001$ \\
\hline
\end{tabular}

*Significant at $\mathrm{P}<0.05$

Table 5 shows there was no statistically significant association between having a specific medical disorder and depression status of respondents. 
Table 5: Medical disorders and depression among patients attending the outpatient clinic $(\mathrm{n}=404)$

\begin{tabular}{lccc} 
Characteristics & $\begin{array}{c}\text { Non depressed } \\
\mathbf{n}(\boldsymbol{\%})\end{array}$ & $\begin{array}{c}\text { Depressed } \\
\mathbf{n}(\boldsymbol{\%})\end{array}$ & Frequency $(\boldsymbol{\%})$ \\
\hline Infective disorder & $48(35.6)$ & $87(64.4)$ & $135(33.4)$ \\
Cardiovascular disorder & $31(33.0)$ & $63(67.0)$ & $94(23.3)$ \\
Endocrine disorder & $10(37.0)$ & $17(63.0)$ & $36(8.9)$ \\
Gastrointestinal disorder & $10(34.5)$ & $19(65.5)$ & $29(7.2)$ \\
Respiratory disorder & $7(35.0)$ & $13(65.0)$ & $27(6.7)$ \\
Musculoskeletal disorder & $9(34.6)$ & $17(65.4)$ & $26(6.4)$ \\
Genitourinary disorder & $14(38.9)$ & $22(61.1)$ & $20(5.0)$ \\
Others & $11(29.7)$ & $26(70.3)$ & $37(9.2)$ \\
Total & $\mathbf{1 4 0 ( 3 4 . 7 )}$ & $\mathbf{2 6 4 ( 6 5 . 3 )}$ & $\mathbf{4 0 4 ( \mathbf { 1 0 0 . 0 } )}$ \\
\hline
\end{tabular}

$\mathrm{X}^{2}=0.915, \mathrm{Df}=7, \mathrm{P}=0.996$

Table 6 shows that after entering the possible predictors of depression into the logistic regression model, the significant predictors of depression were educational status OR $(95 \% \mathrm{CI})=$ $0.5(0.323-0.774)$, family type $\mathrm{OR}(95 \% \mathrm{CI})=$
$0.264(0.121-0.578)$, number of children OR $(95 \% \mathrm{CI})=2.006(1.280-3.143)$ and history of chronic medical condition OR $(95 \% \mathrm{CI})=0.303$ (0.134-0.686).

Table 6: Logistic regression analysis of predictors of depression in respondents

\begin{tabular}{lcccc}
\hline & & \multicolumn{2}{c}{ 95\% Confidence Interval } & P-value \\
\cline { 3 - 4 } Variable & OR & Min. & Max. & 0.002 \\
Educational Status & 0.500 & 0.323 & 0.774 & 0.578 \\
Family type & 0.264 & 0.121 & 3.143 & 0.001 \\
Number of children & 2.006 & 1.280 & 1.086 & 0.072 \\
History of mental illness & 0.397 & 0.145 & 0.686 & 0.004 \\
Chronic medical condition & 0.303 & 0.134 & 1.000 & $<0.001$ \\
Monthly salary & 1.000 & 1.000 & & $<0.001$ \\
Constant & 3819.119 & & & \\
\hline
\end{tabular}

\section{Discussion}

This study found the prevalence of depression among general outpatients as $65.3 \%$. The prevalence rate reported in this study is higher when compared with $59.9 \%$ and $47.8 \%$ prevalence rates reported in the South Western region of Nigeria by Afolabi et $\mathrm{al}^{10}$ and Obadeji et $\mathrm{al}^{15}$ among similar population respectively. Possible reason for the higher prevalence rate in this study could be due to the ongoing insurgency in the region where people live in constant fear and many have lost their loved ones and properties. Other studies conducted in other parts of the country where there are no crises have however reported higher prevalence rates between $59 \%$ and $77 \%$ using other instruments ${ }^{10,16}$. These discrepancies of prevalence rates might be due to variation in attributes of study participants, use of different psychometric scale, study design, setting, time frame and level of regional development of the country.

There was a statistically significant association between depression and age group of the subjects. In this study, depression was more common among participants who were 40years and above than those who were below 40years. This is in contrast to the findings of Gregory and Jonathan ${ }^{17}$ where they reported majority of patients diagnosed with depression to be of younger age group. However, this could be due to the fact that older adults have more medical conditions such as heart disease, stroke, cancer and are on medications for those conditions, both of which cause depression ${ }^{18}$. Also, older patients are more likely to have suffered the consequences of the insurgency going on in the region.

In the present study, depression was found to be more among females and those who were 
unemployed. Different studies have also shown that depression is more common among female gender ${ }^{19,20}$. The suggested reasons for depression being more common in female than male were sex hormones having influences on depression ${ }^{21,22}$. Social researchers also argue that parents unintentionally become more restrictive to their daughters than to their sons, thereby making their daughters vulnerable to depression by reducing senses of self control and self esteem ${ }^{23}$.

Depression was found to be common among patients with lower level of education (primary and secondary education) when compared with those with tertiary education. This agrees with the findings of Engum et $\mathrm{al}^{24}$ and Bielland et $\mathrm{al}^{25}$ who reported that low educational levels were significantly associated with depression. This could be because most patients with lower level of education might not see the need of coming to the hospital for treatment thereby allowing the symptoms of depression to persist ${ }^{25}$.

There was significant association between depression and family type in this study as depression was more common among respondents from polygamous families than those from monogamous families. This finding is similar to the finding of Ozkan et $\mathrm{al}^{26}$ who found that people from polygamous families reported more psychological distress such as depression because they tend to experience lower self esteem, less life satisfaction, less marital satisfaction, and more mental health symptomatology than those from monogamous homes. ${ }^{27}$

Depression in this study was also found to be significantly associated with family history of mental illness. This is in agreement with the findings of Weissman ${ }^{28}$ who reported that the risk for depression was higher among people with family history of mental illness suggesting the potential significance of family history of mental illness. Depression was also significantly associated with having a poor relationship with the respondents' spouses. This is attributable to the fact that building a strong and loving relationship can fortify one against the withering effects of depression ${ }^{29}$. Additionally, persistent marital disagreement and discord can lead to lack of communication and trigger heightened anxiety and depressive symptoms ${ }^{29}$.

The employment status of the studied patients was found to have a significant association with depression as it was more common among the unemployed than employed patients. This is in contrast to the findings of Deyessa ${ }^{30}$ who reported that employment was not significantly associated with depression. However, this could be due to loss of income, lack of social support and low sense of control over life that results from unemployment leading to negative mental health and decline in the standard of living of the individual $^{31}$. Respondents' number of children was also found to be significantly associated with depression. This is similar to the findings of Reinherz et $\mathrm{al}^{32}$ who reported that some aspects of family composition such as number of children in a household and large family size as being linked to depression. This could be due to enormous socioeconomic burdens and responsibilities involved in the care of children and family at $\operatorname{large} e^{32}$.

In this study, there was no significant association between depression and type of medical illness.

This is in contrast to the findings of Frasure ${ }^{33}$ et al who earlier reported that depression was significantly associated with chronic medical conditions such as neurological, cardiovascular, endocrine and oncological illnesses. However, this could be due to the difficulty involved in recognizing depression in medically ill patients and the exact biological mechanisms by which these illnesses may cause depression are yet to be determined $^{29}$.

Depression is also found to be significantly associated with monthly income as depression was more common among those respondents with low monthly income (<50USD) than those with income above 50USD. This is similar to the findings of Williams et $\mathrm{al}^{34}$ who reported that depression is most common in low income people. This could be due to associated socioeconomic 
difficulties and material hardships in meeting basic needs such as food, housing, clothing which could have negative impact on mental health ${ }^{35}$

This study has shown that the prevalence of depression among general medical outpatients is very high in this environment and unfortunately this goes largely undiagnosed and unmanaged.

The findings in this study call for further training and retraining of general duty physicians in the early detection, recognition and treatment of depression.

\section{Strengths and Limitations}

The strengths of this study include a high response rate, reasonably large sample size and almost the first study on depression to be conducted among general outpatients in the north eastern region of Nigeria. However, important limitation is that the study was cross sectional in design and causal relationship cannot be attributed. Additionally, Patient Health Questionnaire-9 was used in this study which is only a screening instrument.

\section{Acknowledgements}

We are highly indebted to Dr Babagana Machina Kundi, Medical Director of Yobe State Specialist Hospital, Damaturu, Dr Zakariya Abdurrahman Ibrahim of Internal Medicine Department, Dr Hussaini Abba Disa of Dental Department of Yobe State Specialist Hospital, Damaturu, Nigeria and Psychiatric Nurse Abdullahi Mai Muhammad Nur for their collaboration, technical support, constructive feedback and facilitating data collection.

\section{Source of Support-Nil}

Conflict of interest-None declared

\section{References}

1. Federal Ministry of Health, author. National Mental Health Strategy of Ethiopia, Addis Abba; 2012.

2. World Federation of Mental Health; author. Depression; a global crisis World Mental Health Day; 2012
3. Remick R.A. Diagnosis and management of depression in primary care; a clinical update and review. Canadian Medical Association Journal; 2002; 167 (11): 12531260

4. Barrett J.E, Barret I.A, Oxman T.E, Gerber P.D. The prevalence of psychiatric disorders in a primary care practice. Arch Gen Psychiatry, 1988; 45; 1100-6.

5. Okello E.S, Neema S.E. Exploratory models and help seeking behaviour: pathways to psychiatric care among patients admitted for depression in Mulago hospital, Kampala, Uganda. Qualitative Health Research, 2007; 17 (1); 14-25

6. Muhwezi W.W, Agren H, Musisi S. Detection of major depression in Uganda primary healthcare settings using simple questions from a subjective well being(SWB) subscale. Social Psychiatry and Psychiatric Epidemiology; 2007; 4261.

7. Okulate G.T, Olayinka M.O, Jones O.B. Somatic symptoms in depression. Evaluation of their diagnostic weight in an African setting. British Journal of Psychiatry,2004; 184; 422-7

8. Kuo D, Tran M, Shan A et al. Depression and the suicidal patient. Emerg Med Clin North Am,2015;33; 765-78.

9. Ho R.C, Mak K.K, Chua A.N et al. The effect of severity of depressive disorder on economic burden in a university hospital in Singapore. Expert Rev Pharmacoecon Outcomes Res,2013;13;549-59.

10. Afolabi M.O, Abioye Kuteyi E.A, Fatoye F.O et al. Pattern of depression among patients in a Nigerian Family Practice. South African Family Practice, 2008; 50,63 .

11. Michael Udedi. The prevalence of depression among patients and its detection by primary health care workers at Matawale Health Centre, Zomba. Malawi Med. Journal, 2014;26 (2);34-37. 
12. Salihu A.S and Udofia O. Prevalence and associated factors of depression among general outpatients in a tertiary institution in Kano, North Western Nigeria. Open Journal of Psychiatry, 2016; 6,228-236.

13. Triant V.A. The recognition and determinants of depression at a South African Primary care clinic, in School of Medicine, Yale University;2002.

14. Adewuya A.O, Ola B.A., Afolabi O.O. Validity of the PHQ as a screening tool for depression among Nigerian students. Journal Affective Disorders, 2006; 96 (12); 89-93.

15. Obadeji A, Oluwole L.O, Dada M.U et al. Assessment of Depression in a Primary Care setting in Nigeria using the PHQ-9. Journal of Family Medicine and Primary Care, 2015; 4(1): 30-34.

16. Ohaeri J.U and Jegede R.O. Depression and the general medical practice in Nigeria. Medicare, 1991;6; 7-11.

17. Gregory A.N and Jonathan B.B. Unadjusted and adjusted prevalence of diagnosed depression in type 2 diabetes. Diabetes Care, 2003; 26: 744-9.

18. David Levine, United States News and World Report, 2017

19. Nandi G, Banergee G, Boral G et al. Socioeconomic status and prevalence of mental disorders in urban rural communities in India. Acta Psychiatri. Scand, 1979;59;276-93.

20. Kishore J, Reddaiah V, Kapoor V, Gill J. Characteristics of mental disorders in a rural primary health centre of Haryana, Indian J. Psychiatry, 1996; 38 (3); 137-42.

21. Poongothai S, Pradeepa R, Ganesan A, Mohan V. Prevalence of depression in a large urban South Indian population; The Chennai Urban Rural Epidemiology Study (CURES-70) PLOs One 2009;4(9).

22. Kaplan H.I, Sadok B.J. Mood disorders. Synopsis of Psychiatry. Behavioual sciences and clinical psychiatry, $8^{\text {th }}$ edition. Baltimore, Maryland; Williams and Wilkins; 1998; pg 524-73.

23. Blehan M and Oren D. Gender differences in depression. Medscape women's Health; 1997;2;3.

24. Engum A, Mykletun A, Midthjell K et al. A large population based study of socio demographic, lifestyle and clinical factors associated with depression in type 1 and 2 diabetes. Diabetes Care; 2005; 28;1904-9.

25. Bielland I, Krokstad S, Mykletun A, Dahl A. Does a higher education level protect against anxiety and depression? The HUNT study; Soc Sci Med, 2008;66 (6); 1334-45.

26. Ozkan M, Altindg A, Oto R, Sentunali E. Mental Health aspects of Turkish women from polygamous versus monogamous families. Int. J. Soc Psychiatry, 2006;52;214-220.

27. Alean Al-krenawi. Mental Health and polygamy; The Syrian case,2007, World Journal of Psychiatry.

28. Weissman M.M. Family history of depression doubles risk for depression. JAMA Psychiatry,2016.

29. Proulx C.M and Buehler C.H. Moderators of the link between marital hostility and change in spouses's depressive symptoms. Journal of Family Psychiatry; 2009,23;540-550.

30. Deyessa B. Depression among women in rural Ethiopia as related to socioeconomic factors. A community based study on women in reproductive age groups. Scand J. Public Health, 2008;36 (589).

31. Haitemarian S. The prevalence of depression and associated factors in Ethiopia: findings from the National Health Survey International. Journal of Mental Health Systems; 2012; 6(231);623.

32. Reinhertz H.Z, Giaconia R.M, Pakiz B.M et al. Psychosocial risks for major depression in late adolescence; a 
longitudinal community study. J. Am. Academy Child Adolesc Psychiatry; 1993; 33;1155-1163.

33. Frasure S.N, Lesperance F, Talaji M. Depression and 18 month prognosis after myocardial infarction circulation; 1995; 91;999-1005.

34. Williams D.R, Gonzalek H.M. Prevalence and distribution of major depressive disorders in African Americans, Caribbean blacks and non Hispanic white; results from the National Survey of American life. Archives of General Psychiatry; 2007;64;305-315.

35. Kessler R.C, McGonagle K.A. Lifetime and 12month prevalence of DSM-111-R. Psychiatric disorders in United States. Results from the National Comorbidity Survey. Archives of General Psychiatry, 1999;51;8-19. 